\title{
Nutritional and Biological Control Synergism against Gastrointestinal Nematodes in Small Ruminants
}

\author{
Sahoo A* and Khan FA
}

Central Sheep and Wool Research Institute, Avikanagar-304501, Rajasthan, India

${ }^{*}$ Corresponding author: Sahoo A, Principal Scientist \& Head, Division of Animal Nutrition, Central Sheep and Wool Research Institute, Avikanagar, Rajasthan, India 304501, Fax: +91-1437-220163, Tel: +91-1437220143, E-mail: sahooarta@yahoo.com

Citation: Sahoo A, Khan FA (2016) Nutritional and Biological Control Synergism against Gastrointestinal Nematodes in Small Ruminants. J Vet Sci Anim Husb 4(1): 104. doi: 10.15744/2348-9790.4.104

Received Date: October 09, 2015 Accepted Date: January 15, 2016 Published Date: January 18, 2016

\begin{abstract}
Parasitic gastroenteritis caused by gastrointestinal nematodes (GIN) continues to be a major constraint against profitable small ruminant production. The increasing prevalence and severity of anthelmintic-resistant nematodes in many parts of the world has led to a search for non-chemical control options. Approaches alternative or adjunct to chemotherapy for the control of GIN in ruminants are being increasingly important in India because of rapidly developing anthelmintic resistance in nematodes and the increasing concern of chemical residues in animal products and environment. Significant advances have been made in biological control by exploiting nematophagous fungi in different parts of the world including India. Initial studies in India demonstrate that GIN control by larvaetrapping fungi looks promising but suitable system for delivering the fungi to ruminants and practical dosing regimes integrated with nutritional and managemental control measures hold promise for sustainable control measure. Synergism of fungal control measures with feeding and nutritional manipulation accentuate correction of nutrient deficiency in grazing animals as well as recuperation of supra-nutritional demand in the event of GIN infection. This papers reviews the work done on both these aspects including delineation of possibilities for a synergistic approach for control of GIN infection in small ruminants. Adoption of this synergistic model for GIN control measures will definitely reduce parasite pathogenesis and the use of chemical anthelmintics, as well.
\end{abstract}

Keywords: Nutrition; Nematophagous fungi; Gastrointestinal nematodes; Small ruminants

Abbreviations: GIN: Gastrointestinal nematodes; DM: Dry matter; VFI: Voluntary feed intake; FEC: Faecal egg count; EPG: Eggs per gram; CP: Crude protein; P: Phosphorous; Mo: Molybdenum; Cu: Copper; Se: Selenium; CWOP: Copper oxide wire particles; UMMB: Urea-molasses mineral blocks; CT: Condensed tannins; Hb: Haemoglobin; PCV: Packed cell volume; CFB: Complete feed blocks; CSWRI: Central Sheep and Wool Research Institute; NDDB: National Dairy Development Board

\section{Introduction}

Over the last 50 years a number of very effective anthelmintic drugs have been discovered and made available to farmers to successfully control gastrointestinal nematodes (GIN). However, resistance to these anthelmintics is becoming increasingly prevalent in grazing ruminants [1-4] and thus the development of variable degrees of resistance among different species of GIN has been reported for all the major groups of anthelmintic drugs. Frequent usage of the same group of anthelmintic; use of anthelmintics in sub-optimal doses, prophylactic mass treatment of domestic animals and frequent and continuous use of a single drug have contributed to the widespread development of anthelmintic resistance in helminthes [5]. Restrictive legislation regarding the chemical control of nematodes in organic livestock production together with a wish to eliminate drug residues in agricultural products is additional driving force for the interest in alternative parasite control methods [6]. Moreover, anthelmintic resistance has great epidemiological bearing as resistant parasites may be more fecund and pathogenic as compared to susceptible populations of the same. At the same time, they may have an increased establishment rate in the host and the increased survivability of free-living stages. The degree and extent of this problem especially with respect to multidrug resistance in nematode populations is likely to increase. Experience from the development of anthelmintic resistance suggests that modern control schemes should not rely on sole use of anthelmintics, but employ other, more complex and sustainable recipes, including parasite resistant breeds, feeding and nutritional management, pasture management, nematode-trapping fungi, antiparasitic vaccines and botanical dewormers. In this context there is an urgent need to re-evaluate our parasite control measures to ensure the sustainability of small ruminant production necessitating finding possible synergistic alternatives to chemical treatment. 


\section{Fungal control of gastrointestinal nematodes}

The philosophy behind biological control of GIN is that by using one of the natural enemies of nematodes, it will be possible to reduce the infection level on pasture to a level at which the grazing animals avoid both clinical and subclinical effects due to parasitic nematodes. Thus, this method of controlling GIN using nematophagous fungi is fast becoming an area of applied research with the possibility of becoming an important integrated element in developing new sustainable control strategies [711]. It is directed against the free-living stages without any effect on the parasitic phase within the host and therefore, the idea of using nematophagous fungi to control parasitic nematodes is based on the reduction of the larval level in the faeces before larvae reach the vegetation, which re-quires a high density of spores in the faeces. Although no biological control agent will eliminate the number of infective stages to zero, the grazing animals will constantly receive a small amount of parasitic larvae and thereby should be able to develop a natural immune response.

Biological control of parasitism started as early as in the 1940's but with little success. In the 1960's evidence was found for predaceous fungi working against parasitic nematodes [12], but further experiments were not taken up. The major breakthrough was achieved at the beginning of the 1990's when Larsen et al. [13] selected fungi capable of surviving in vitro conditions simulating the passage through the gastrointestinal tract of cattle. Research with nematode-trapping fungi has documented the potential as a biological control agent against the free-living stages under experimental and natural conditions [14]. These fungi occur in the soil throughout the world where they feed on a variety of free-living soil nematodes. These fungi capture nematodes by producing sticky, sophisticated traps on their growing hyphae. The two genera tested, Arthrobotrys and Duddingtonia, displayed the ability of gut survival with the genus Duddingtonia performing significantly better. After passing through the gastrointestinal tract, spores germinate and looped hyphae trap the developing larval stages in the faecal environment. This technology has been applied successfully under field conditions in all livestock species, and is an environmentally safe biological approach for control of worms under sustainable, forage-based feeding systems. D. flagrans displayed excellent gut survival ability and the findings triggered the detailed research in this area and since then many trials have been conducted in several countries in which faecal samples of sheep have been screened for pre-dacious fungi [15-17]. Even after the promising results of the feeding trials with D. flagrans [18-20] researchers con-tinued to work with a wider range of fungi until the end of the 1990's when trials with fungi other than D. flagrans started to decrease. In the first years, most of the in vivo trials focused on the potential of larval reduction by the fungus without giving any significance to the amount of chlamydospores necessary for a successful reduction.

D. flagrans belonging to the class of Fungi Imperfecti (Deuteromycotina) is a nematode-trapping fungus utilizing nematodes either as the main source of nutrients, or supplementary to a saprophytic existence. The fungus is found world-wide in many different habitats, but is especially frequent in organically rich environments such as compost and faeces. Fungi are naturally picked up by grazing ruminants and subsequently excreted in the voided faeces [15,21-24]. There is necessity of isolating fungi locally as the performance of biological control agent in a particular climatic condition may differ from those prevailing where the fungus originated. Under experimental conditions, the net trapping nematophagous fungus $D$. flagrans have shown the ability to effectively control the developing GI infective larvae on pasture and subsequent levels of infection in various livestock species. $D$. flagrans has been used successfully against ruminant GIN and is a promising candidate for biological control of these organisms [25-27]. In India work on biological control of GIN was initiated in 1999 with attempts to isolate local strains of nematophagous fungi, A. oligospora and D. flagrans from fresh faecal samples of grazing small ruminants [28-30]. Both the fungi produce sticky 3 -dimensional nets raised above the growth medium (Figure 1). The isolates of $D$. flagrans had potential to survive passage through the gastrointestinal tract of sheep and subsequently to destroy $H$. contortus larvae in faecal cultures from fungus fed sheep [30-32]. There is production of large numbers of thick-walled, asexual resting spores that serve as survival propagules, called chlamydospores (Figure 2), which are likely the basis for its survival through the digestive tract of ruminants. Further, Khan et al. [33] delivered 6 million chlamydospores daily and consecutively for six weeks to sheep experimentally infected with Haemonchus contortus and found a very low level of larval count in the pasture compared to control (600 vs $\left.4000 \mathrm{~L}^{3} / \mathrm{kg} \mathrm{DM}\right)$.

\section{Nutritional control measures}

Voluntary feed intake (VFI) depression has generally been recognised as a major feature of the pathogenesis of GI infections and reductions of intake between 10 and $30 \%$ have been commonly found [34,35]. Dietary modification aimed at increased nutrient availability e.g. nutrient enrichment, can offset the negative impacts of infection even at low levels of feed intake. Similarly, increasing VFI through availatibility of palatable feed resources/complete feed can make up the deficiency by overcoming anorexia in parasitised animals. It has been demonstrated that extra protein supplementation could overcome some degree of anoraexia and pathogenicity in the experiments with $H$. contortus [36-38]. A reduction in VFI can thus severely influence the protein-energy economy of the host by substantially reducing the total nutrient availability for the anabolic processes [39]. It has been suggested that anorexia may result from pain and discomfort associated with infection or be the result of hormonal feed-back mechanisms from disrupted gastrointestinal function [40]. The degree of anorexia may be affected by the level of infection, species of parasite and its site of infection and by the breed, age and resistance status of the host. Anorexia appears to be greatest during the acquisition phase of immune response [39]. Nutrition of the host could have the potential to affect how rapidly immunity is acquired and expressed in defence of the parasitism. Host protein and energy nutrition can affect greatly, the expression of immunity in sheep a- 
nd goats, and in severely undernourished animals that loose protein mass, the acquisition of immunity is severely impaired [41]. Van Houtert et al. [34] observed that supplementation of a hay diet with 150 g protected protein or $100 \mathrm{~g}$ fish meal per day affected the rate of worm expulsion after 10 weeks of trickle infection with Trichostrongylus colubriformis and the apparent rate of expulsion was related to the level of supplementation. Animals that get challenged by nematode parasites need a surplus of desired nutrients either for an immune response or to maintain performance (e.g. growth, pregnancy, and lacta $\neg$ tion). Therefore, resistance and performance competes for resources, particularly for protein. Kahn [42] con $\neg$ firmed this phenomenon in a study to state that supplementation of ewes during the peri-parturient period enhanced their ability to resist infection and conse $\neg$ quently reduces faecal egg output in animals that are previously selected for nematode resistance. Several ovine studies have shown that improved protein nutrition reduces parasite infestation. This is assumed to be mediated by enhanced host immunity, which may be especially important with selection for immunity to gastrointestinal parasitism $[43,44]$. The precise regulatory mechanisms through which the improved host nutrition enhances resilience and resistance to parasites are still largely unclear and merits systematic studies. There is need to obtain quantitative information on the nutritional costs of initiating and maintaining the cellular and humoral immune response in parasitized hosts.

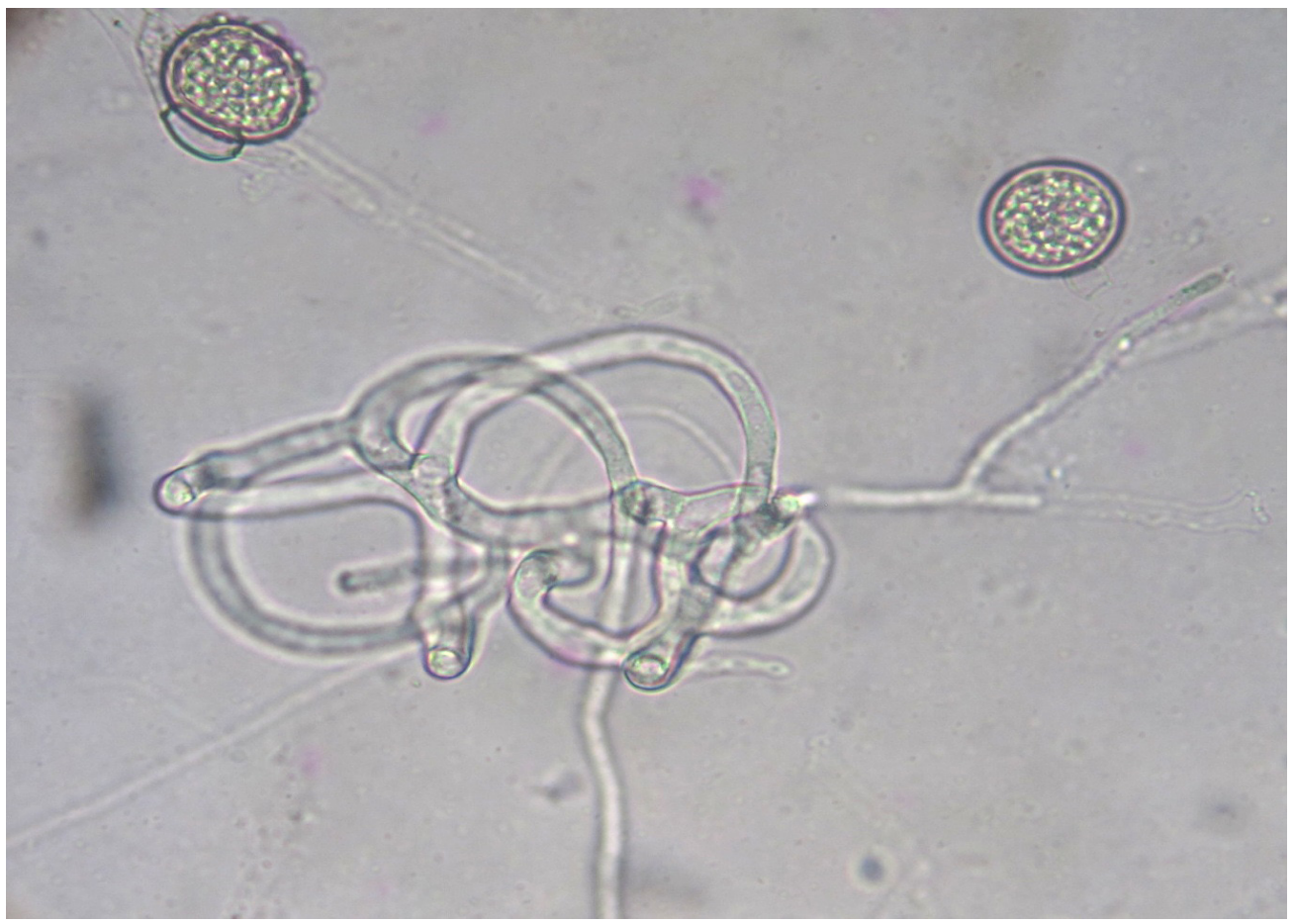

Figure 1: Three dimensional hyphal loop of Duddingtonia flagrans after inoculation of Haemonchus contortus infective larvae on agar medium

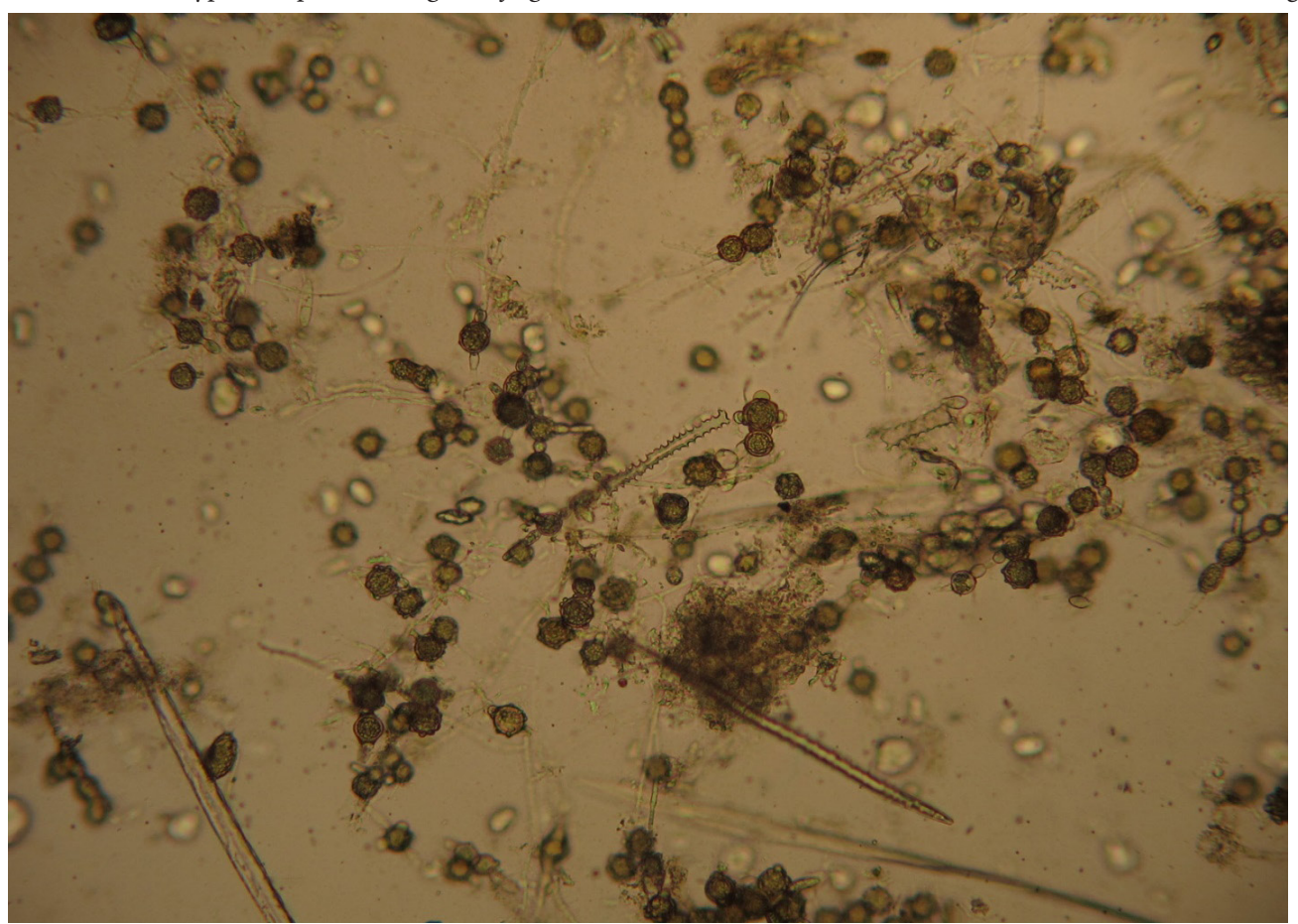

Figure 2: Chlamydospores of Duddingtonia flagrans obtained from barley culture $(\times 400)$ 


\section{Role of macronutrients}

The nutritional status of the host has long been considered as an important factor in influencing the host-parasite relationship and the pathogenesis of parasite infections. While the mechanisms underlying this fact are not clear, energy balance and supply is increasingly considered to be an important factor in the immune response [45]. An improvement in energy supply was reported to improve resistance to Teladorsagia circumcincta infection of growing lambs [46] and, a similar response to supplementary feeding was found to natural GI infections in Criollo kids [47]. The effect of D. flagrans as a biological control agent appeared clearly enhanced both in magnitude and duration by energy supplementation [48]. Studies on the role of fat reserves on the immune response to GI infection in sheep [49] have shown that fat mass stored by ewes was related to the response of immunity to GI parasites and this commenced at an early stage of infection affecting the establishment and development of incoming larvae, thereby reducing faecal egg excretion and affecting pasture infectivity. Furthermore, the differential response on FEC and worm counts between fungi-treated groups that showed a similar level of fat reserves at slaughter, appears to be in line with the fact that the nutritional effects of controlling the number of worms established was found to be more effective at lower than at higher levels of infection. In the same line, Gomez-Rincon et al. [48] observed the interaction between fungus and barley supplement on EPG and total worm burden to establish that the combination had a greater effect as a method of parasite control than when applied separately.

A variable degree of protein deficiency does occur in grazing ruminants depending on seasonal availability of pasture and other forages. Van Houtert et al. [50] showed that protein supplement reduced production losses, enhanced expul $\neg$ sion, reduced the need for drenching significantly, increased wool production and fibre diameter and reduced FEC. In field studies Knox and Steel [51] observed increased live-weights of lambs at weaning, increased reproduction rates in maiden ewes and reduction in faecal egg output in grazing sheep supplemented with urea-molasses blocks. Coop and Holmes [43] reviewed several studies and was of the opinion that protein supplementation appears to have no influence on the initial parasite establishment but on estab $\neg$ lished infection and the immune response, which is indicated by a reduced FEC and worm burdens and by enhanced resistance to re-infection. Numerous studies have examined the interactions between protein nutrition and the response to nematode parasitism in small ruminants [52-58]. Houdijk et al. [59] opined that optimized host protein nutrition could be able to reduce the establish $\neg$ ment of parasites around the periparturient loss of immu $\neg$ nity. Protein intake does not influence initial infec $\neg$ tions in naïve sheep, but with trickle infections (serial doses of infective larvae more comparable with natural transmission), experimental evidence for sheep showed that higher protein intake (>120 g CP/kg DM) increased immune responses as measured by reduced egg counts and worm burdens [43]. Several studies thus suggest that under drought conditions, species unable to maintain adequate nutrition, mainly low-quality feeders, are less able to cope with gastrointestinal parasite infections. In particular, during dry periods, reduced protein intake seems to be associated with declining resilience and resistance to infection. Louvandini et al. [55] reported that diet supplementation with high protein improved resilience and resistance to natural infection by endoparasites during the rainy season and in the dry season there was a decrease in both of these traits, which were intimately linked to the quality of available forage under tropical conditions. Inadequate uptake of CP is considered to be the principal determinant in grazing animals with sub-clinical GIN infection [35].

\section{Role of micronutrients}

Types of diet and availability of vitamins, minerals and other nutrients are directly related with susceptibility of animal to the parasites. Supplementation of minerals and vitamins can play a key role in affecting ruminant susceptibility. Minerals like zinc, iron, cobalt, sodium, potassium, phosphorus, etc. are very much essential for proper functioning of cellular and immunological response to develop functional immunity against the parasites [60]. Many nutritional deficiencies, specifically, zinc deficiency causes atrophy of lymphoid tissues leading to lower numbers of immune cells and functional defects during antigen-specific responses $[61,62]$. Given the paramount role of the gastrointestinal-associated lymphoid tissues in inducing and regulating immune responses to intestinal parasites and in orchestrating responses in the spleen and peripheral circulation, it may be concluded that zinc deficiency (in association with energy restriction) exerts profound effects on the gut mucosal immune system, leading to changes in systemically disseminated immune responses and, importantly, to prolonged parasite survival. Studies on the relationship of phosphorous (P) with T. vitrinus worm burden in sheep suggest that increased $\mathrm{P}$ supply decreases mean worm burden [63]. It was observed that the weight gain of lambs infected with parasites increased by $40 \%$ when the P level of the diet was $0.28 \%$ compared to those fed a low P (0.18\%) diet [64]. Addition of molybdenum (Mo; $0.05 \mathrm{mmol} / \mathrm{kg} \mathrm{DM}$ ) to the diets of lambs reduced the number and length of T. vitrinus worms established and the FEC and number of $H$. contortus worms recovered from the abomasum [65] after trickle infections with the two parasites. McLure et al. [66] suggested a critical dietary Mo concentration of 6-10 mg Mo/kg DM for maximum host resistance to T. colubriformis. Sheep on this Mo intake showed a $90 \%$ reduction in FEC and worm burdens compared to lambs offered diets with Mo concentrations below or above this range. It may be suggested that Mo could enhance the inflammatory response by increasing superoxide radical concentration in the mucosa either directly or by reducing the effectiveness of local trace element dependent anti-inflammatory enzymes. Trace elements like $\mathrm{Cu}, \mathrm{Mo}$, and Se are known to influence the host resistance to nematode infection with a probable direct anthelmintic effect and by influencing host metabolism [52]. They found reduced worm burden (H. contortus, O. circumcincta) in lambs by administering copper oxide wire particles (CWOP) in the diet. Iron supplements are also recommended where animals are affected by blood sucking worms, like Haemonchus spp. Burke et al. [67] evaluated the efficacy of combined treatment of COWP and D. flagrans 
against GI nematodes in lambs in USA. There was no adverse effect of COWP on the ability of fungus to inhibit residual larval development after COWP treatment. Cobalt deficiency may also promote parasitism as it is essential for vitamin $\mathrm{B}_{12}$ synthesis.

Vitamins A, D, and B complex are integral in developing immunity to parasites. Vitamin A is essential to improve the intestinal epithelial integrity [68] and its deficiency most likely disrupts the intestinal immune system and weakens the host defense against intestinal parasites. Vitamin $\mathrm{B}_{12} /$ Co deficient animals may become predisposed to high FEC in pregnant sheep [69]. The co-enzyme forms of the vitamin-adenosyl cobalamin and methyl cobalamin - are important in the conversion of propionate to glucose and the methylation of homocysteine to form methionine, respectively. Failure of either pathway could decrease critical amino supply to the immune system and the homocysteine-cysteine pathway may be particularly important.

Looking at the essentiality of minerals and vitamins, the grazing animals should always have access to mineral block and vitamin supplements to compensate for the deficiencies in pastures. These licks can form a vehicle of oral inoculation of fungal zoospores for lowering the parasitic larvae in the grazing pasture. We need to evaluate survival of fungal zoospores and accordingly, the dosage schedule for administering through salt licks, urea-molasses mineral blocks (UMMB), urea molasses liquid supplement, urea-molasses semi-solid cake, etc.

\section{Role of phytoadditives}

The therapeutic use of medicinal plants as a substitute to synthetic drugs for controlling GIN in small ruminants can be envisaged through strategic feeding regimen at times of higher seasonal incidence or as part of daily feed supplements/additives. The herbal supplements also possess some unique active constituents that preclude worms to develop resistance against them. Different medicinal plants have been investigated by researchers for their adulticidal, larvicidal and ovicidal activity to GIN [70-73]. Sujon et al. [74] screened ten indigenous medicinal plants having anthelminthic action and found significant and potent antinematodal effect in ethanol extracts of Labanga, Neem, Karolla and Pineapple at dose of 100mg/kg. Balamurugan and Selvarajan [75] evaluated methanolic extract of Indigofera tinctoria and observed a significant anthelmintic property in a dose dependent manner giving shortest time of paralysis and death with $100 \mathrm{mg} / \mathrm{ml}$ concentrations, comparable with the standard drugs. Phytochemical analysis of the crude extract revealed presence of polyphenolic compounds, tannins, as one of the phytoconstituent and they correlated this activity to some synthetic phenolic anthelmintics e.g. niclosamide, oxyclosamide and bithinol that are shown to interfere with the energy generation in helminth parasites by uncoupling oxidative phosphorylation [76]. Another possible anthelmintic effect of tannins is that they can bind to free proteins in the gastrointestinal tract of host animal [77] or glycoprotein on the cuticle of the parasite and cause death [78]. Condensed tannins (CT) have shown biological effects that may aid in the control of dewormerresistant internal parasites and thus forages rich in CT have potential to be a component of GIN control programs [79-82]. Zaman et al. [83] evaluated the anthelmintic activity of a herbal formulation based on aqueous extracts of leaves of Azadirachta indica and Nicotiana tabacum, flowers of Calotropis procera and seeds of Trachyspermum ammi and found a maximum of $96.2 \%$ reduction in FEC at a dose rate of $4 \mathrm{mg} / \mathrm{kg}$ body weight to sheep naturally parasitized with mixed species of GIN. Salifou et al. [84] studied the efficacy of an aqueous extract of leaves of Chenopodium ambrosioïdes against nematode parasites in goats and observed significant decrease of faecal strongyle eggs, over $70 \%$ in 3 days and almost 100\% in 5 to 6 days. They observed a parasite clearing effect in the abomasum and small intestine and recommended a dose as low as $1 \mathrm{ml} / \mathrm{kg}$ body weight for three days to be appropriate for prescriptive control of GIN. Pathak et al. [58] incorporated leaf meal mixture of Ficus infectoria and Psidium guajava in the ratio of 70:30 to provide CT (1.5\% of DM) in $H$. contortus infected sheep and observed a discernible positive impact on $\mathrm{N}$-retention and haematological parameters (Hb and PCV) and an inhibitory effect on intensity of $H$. contortus infection. Similarly, Kimani et al. [85] found significant reduction in FEC (84\%) when sheep fed herbal leaf mixture containing Entada leptostachya and Prosopis juliflora (500 mg/kg body weight).

A number of several other plants that have been used sporadically for controlling internal parasites in ruminants but most of this information is anecdotal and needs further verification if these plants/herbs are to be used effectively. Many botanical dewormers that could be added in animal feed includes garlic, pumpkin seed, worm wood (Artemisia spp.), neem seed, tansy (Tanacetum vulgare), wild gingers (Asarum canadense), mustard, common juniper (Juniperus communis), male fern radishes, raw grated turnips or horseradish, pyrethrum (Chrysanthemum cinerariifolium) [86,87]. Thus, use of herbs/medicinal plants in routine feeding practice as a preventative/treatment measure without allowing the GIN to establish resistance may be considered a feasible approach. However, more extensive studies are needed to be directed towards experimental validation of plants, isolation and characterization of active constituents, clinical evaluation and ascertaining of their specific mode of action against GIN so as to establish as an effective alternative to chemical anthelmintics. Further, incorporation of these phytochemical rich plant biomass or their active principles in the dietary of animals would probably ensure 'organic consumerism' of the livestock products from small ruminants not exposed to chemical drugs. The feed supplements/ additives can be included in the ration as complete feed (block/ pellet), through concentrate mixture, nutrient enriched pellets or blocks (CFB, UMMB etc.) to provide both nutrition as well as therapeutic/preventive control of GI parasitism. Amalgamation of biological control through nematophagous fungi in this delivery system may further widen the scope of sustainable parasite control programme in grazing ruminants. 


\section{Combining biological and nutritional control strategy Delivering fungal zoospores}

There are two possible ways to reach high spore density in faeces, the first is to artificially inoculate the faeces and the second way is to administer the spores orally. Since the first way seems not viable the only possibility adheres to discovering fungal zoospores that are able to survive the gastrointestinal tract of ruminants and then defecated onto the pasture. This complex problem may have been one reason for the rather slow progress of science concerning this topic. The only delivery system is incorporating the fungal spores into supplemental feedstuffs that must be fed daily to ensure that all animals consume an equivalent amount of feed for a standard period no fewer than 60 days. This eventually involves feeding and nutritional management, which can be directed at GIN control strategy. Thus, both biological and nutritional control measures would act synergistically against parasite pathogenesis and sustain small ruminant productivity.

It was demonstrated that the fungus was effective in reducing larval numbers in faeces in sheep that were offered blocks containing D. flagrans [87]. They suggested that supplementary feeding or block administration might provide options for product delivery. In another study, Waller et al. [14] demonstrated that D. flagrans that was pressed into an intraruminal controlled-release device retained viability for up to 9 months of storage at $4{ }^{\circ} \mathrm{C}$. In addition, the device was effective at substantially reducing the number of infective larvae that developed in cultures of faeces collected from sheep infected with $H$. contortus for up to 3 weeks after treatment. Such a device would provide an option for animals that are either not supplemented or are housed in remote locations (i.e., range conditions). In Malaysia pen feeding trials were conducted using naturally and artificially infected $H$. contortus and local isolate of fungus either in a grain supplement or incorporated into feed blocks [24]. Fungus survived the gut passage in sheep and at about $1 \times 10^{6}$ spores/ animal/ day, reduced the number of developing larvae in faecal cultures by more than $90 \%$. Chandrawathani et al. [88] found satisfactory results while assessing the efficacy of fungus feeding daily as a feed supplement or incorporated into feed blocks in a small scale field trial. Young sheep receiving the fungus through both the methods did not suffer clinical haemonchosis and control animals required the salvage anthelmitic treatment. Long term field studies were conducted on two government managed sheep farms in different agro climatic regions in Malaysia [89]. The results have shown a benefit of using fungus as a daily feed supplement with rapid rotational grazing. In Brazil, Rocha et al. [90] assessed the efficacy of local isolate of D. flagrans against trichostrongyle infections in sheep at pasture throughout 6 months. Pellets prepared from fungus mycelia in liquid culture medium were mixed with the diet at a concentration of $1 \mathrm{~g}$ pellet per $10 \mathrm{~kg}$ live weight twice a week. Such feeding of animals with pellets containing fungus had no benefit to the prophylaxis of nematode infections. Aguillar et al. [91] evaluated the use of multinutritional pellets (MP) containing urea, wheat coat, soy meal, molasses, and chlamydospores as vehicles for oral administration in sheep against $H$. contortus. The workers concluded that the use of MP containing D. flagrans chlamydospores could be considered as a viable alternative control tool against sheep haemonchosis. Santurio et al. [92] observed a significant reduction in the number of nematode eggs per gram of feces and in the larval availability on herbage (difference of $37.6 \%$ ) in comparison to the control group after the oral administration of lyophilized chlamaydospores of $D$. flagrans. Control animals needed to be dewormed three times during the experiment, whereas the fungus-treated animals maintained a low parasite load, independent of seasonal variation.

Like other countries Indian researchers too made efforts to find out a suitable and cheap method for delivering fungus, which could be integrated with existing animal husbandry practices without causing problems to the farmers (Table 1). The occurrence of night housing of animals in India provides the practical option of deploying fungus spores in a feed supplement. The incorporation of chlamydospores of $D$. flagrans in concentrate feed pellets has been tried at National Dairy Development Board (NDDB), Anand, however, with a very poor shelf life of spores [93]. The fairly long shelf life of desiccated chlamydospores led to be used for top dressing of concentrate feeds. A device was developed and evaluated at Central Sheep and Wool Research Institute (CSWRI), Avikanagar (Rajasthan) to deliver nematophagous fungus D. flagrans to sheep by using local fungal isolate. Two isolates of nematophagous fungi, Arthrobotrys oligospora [94] and one isolate of D. flagrans have been obtained from the fresh faeces of sheep [33]. Bulk production of D. flagrans was tried on soaked and sterilized wheat, maize and barley grains. After 9 weeks of growth, estimation of chlamydospores from cultures was done and chlamydospre concentration was found to be $2,10000,560000$ and 800000 per gram of grains of wheat, maize and barley, respectively confirming barley as the suitable substrate for harvesting fungal zoospores [95]. Chlamydospores were obtained from the grains in powder form by lyophilization. The powder was filled in capsules in order to develop a delivery device (Figure 3). Capsules were fed to $H$. contortus infected sheep and effect of fungus was evaluated on the development of infective larvae in faeces. In another approach, sterilized barley grains supporting the fungal growth were incorporated into straw based complete feed blocks (CFB, Figure 4). The viability of fungal spores was assessed for the biological control of ovine $H$. contortus. Two groups (fungus-treated and control without fungus), each consisting of five which were artificially infected with $H$. contortus. The treated group received fungus incorporated CFB (400 g block per lamb delivering 6 million chlamydospores) daily during 6 weeks. Fungal chlamydospores survived well in CFB with very little moisture (11.8\%) when stored at room temperature. Mean larval development was significantly $(\mathrm{P}<0.001)$ lower compared to control from day 1 to the end of the feeding. Larval recovery from the grass samples started from $2^{\text {nd }}$ week of the experiment and it increased markedly on the plot grazed by the control group reaching as high as $4000 \mathrm{~L}_{3} / \mathrm{Kg} \mathrm{DM}$ compared to less than $600 \mathrm{~L}_{3} / \mathrm{Kg}$ DM in the plot grazed by experimental group fed on CFB with fungal spores. No significant difference was observed in the number of eggs per gram of 
faeces between both the groups. However, significant $(\mathrm{P}<0.001)$ reduction in developed larvae on coprocultures was seen for fungal spore incorporated group. Low levels of larval counts were maintained in the plot grazed by fungus treated group throughout the experiment. The study demonstrated that CFB feeding might prove a potential means of delivery of $D$. flagrans to sheep for successful biological control of H. contortus.

\begin{tabular}{|l|c|c|}
\hline \multicolumn{1}{|c|}{ Control measures } & Parasite & References \\
\hline $\begin{array}{l}\text { Isolation of local strains of nematophagous fungi (A. oligospora, D. flagrans) from fresh faecal } \\
\text { samples of grazing ruminants and establishment of predatory activity to show superiority of } \\
\text { ovine isolate. }\end{array}$ & H. contortus & 28,29 \\
\hline $\begin{array}{l}\text { Sheep drenched with chlamydospores of D. flagrans of Indian sheep origin at 0.5 million } \\
\text { spores/kg body weight twice daily for 30 days and found lowered herbage infectivity. }\end{array}$ & H. contortus & 9 \\
\hline Incorporation of chlamydospores of D. flagrans in concentrate feed pellets. & H. contortus & 93 \\
\hline $\begin{array}{l}\text { Suitable substrates for bulk production of nematophagous fungi tried on soaked and sterilized } \\
\text { wheat, maize and barley grains and found barley as the suitable substrate for harvesting fungal } \\
\text { zoospores }\end{array}$ & H. contortus & 94,95 \\
\hline $\begin{array}{l}\text { Concentrate top-dressed with desiccated chlamydospores of D. flagrans at } 1 \times 10^{5} \text { to } 2 \times 10^{6} \text { per } \\
\text { kg body weight of sheep. }\end{array}$ & H. contortus & 98 \\
\hline
\end{tabular}

Table 1: Biological and nutritional control measures against gastrointestinal parasitism in India
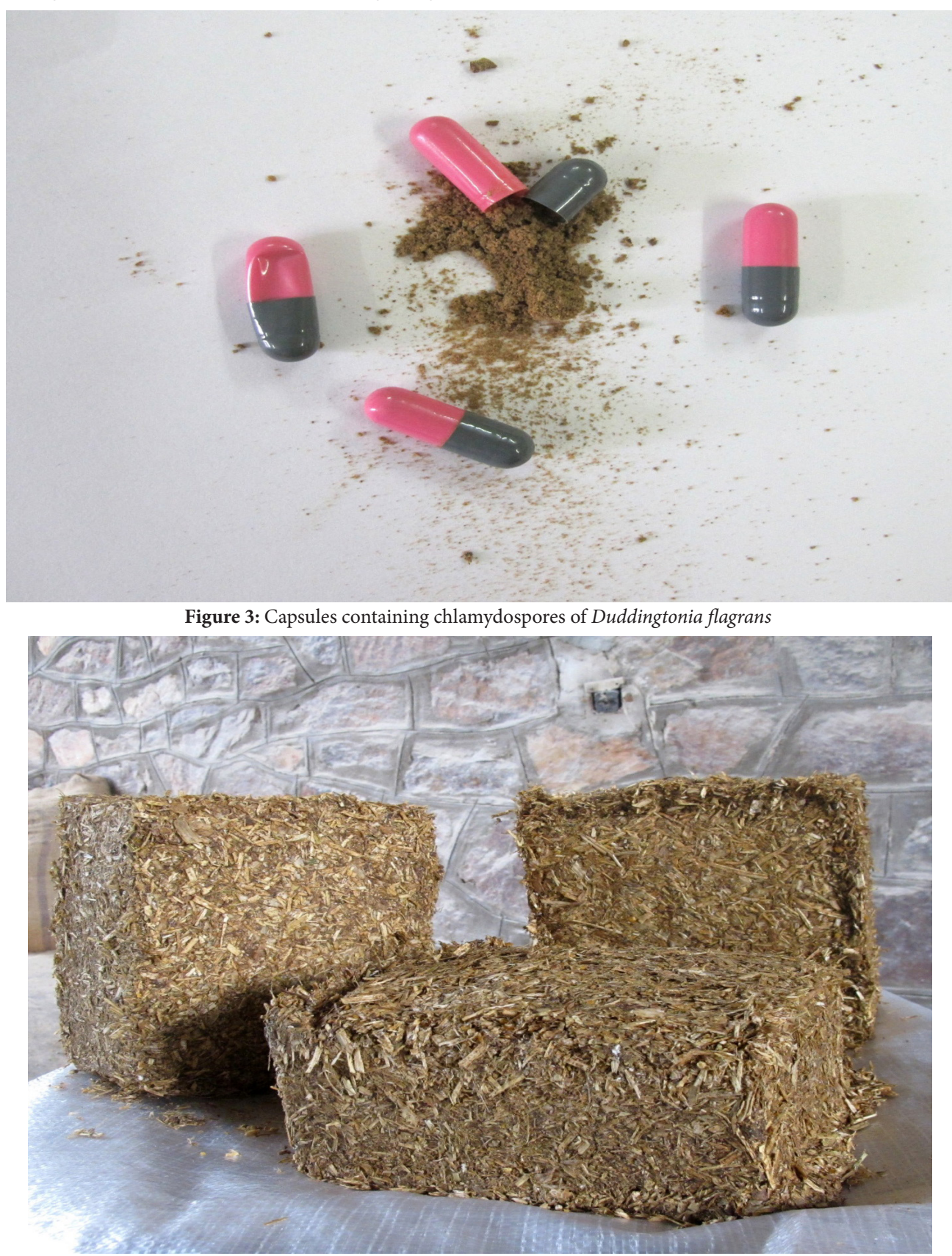

Figure 4: Fungus incorporated complete feed blocks (CFB) 


\section{Activity of $D$. flagrans}

The challenge remains to increase the effectiveness of $D$. flagrans and its optimal delivery for effective parasite control strategy. Oral administration of the fungal spores through feeding of CFB allowed simultaneous deposition of fungal spores and parasite eggs and since, $D$. flagrans is only active within the faecal deposit it prevented transmission of third-stage larvae from the faecal deposit onto the pasture $[20,96]$ thereby reducing subsequent FEC in the treated animals. In the process, it might take an extended period of time to gain the cummulative effect of this strategy depending on the initial infection level of the pasture in question and continuance of this biological control measures.

Dosage: A continuous uptake of fungal zoospores by the host animal that can be released onto the pasture through faeces to exert its nematophagous activity is considered important while assessing the dose and its scheduling. Single and sustained dosing experiments with locally isolated $D$. flagrans at the dose rate between $5 \times 10^{5}$ and $\times 10^{6}$ chlamydospores per day resulted in more than $80 \%$ reduction in larval number in faecal cultures [97]. During a pasture plot study, where faeces collected from sheep given a daily dose of chlamydospores at a rate of $5 \times 10^{6}$ was deposited on pasture plots, Faedo et al. [20] found significantly lower numbers of larvae recovered from pasture contaminated with faeces from fungus fed sheep than from plots contaminated by control group of sheep. Knox and Faedo [8] conducted a field study to determine the effect of feeding $2 \times 10^{6}$ daily for 6 months to lambs on pasture and found reduced FEC as well as improvement in live weight gain. Feeding trials were conducted by Sanyal and Mukhopadhyaya [98] with stall-fed sheep parasitised with $H$. contortus. Animals were offered concentrate feed which had been top-dressed with desiccated chlamydospores for 10 days. It was observed that spore level of $\times 10^{6} / \mathrm{kg}$ body weight virtually eliminated larvae from both the pasture and the faecal cultures. In another study in New Zealand, the fungus has been found effective in reducing larval numbers on pasture grazed by goats fed a daily dose of chlamydospores at the rate of $5 \times 10^{7}$ per animal per day [11]. Terrill et al. [99] tested various levels of daily dosing (ranging from $5 \times 10^{4}$ to $5 \times 10^{5}$ spores $/ \mathrm{kg}$ body weight mixed in a complete diet) to goats in the Southeastern U.S. and found a significant dose response for controlling parasitic larval development in goat faeces. In a second experiment, the researchers fed $2.5 \times 10^{5}$ spores to does every day, every other day, or every third day and found that daily fungal spore feeding provided more consistent larval reduction than intermittent feeding. In France, the ability of the fungus to reduce the number of infective nematode larvae in coproculture was investigated in goats using different doses $\left(0,1.25 \times 10^{5}, 2.5 \times 10^{5}, 5\right.$ $\times 10^{5}$ chlamydospores per kg body weight daily) by oral administration or by voluntary consumption in the feed during natural or experimental infections with nematodes [100]. The results indicated that a minimum daily dose of $5 \times 10^{5}$ chlamydospores per kg body weight must be used to ensure a high treatment efficacy and that daily administration is preferable for maintenance of efficacy over time in farm conditions. The effectiveness of combination of selective anthelmintic treatments and fungus feeding (at the dose rate of $0.5 \times 10^{6}$ spores per kg body weight daily) was evaluated in goats in South Africa [101]. Although no improvement in parasite control was evident by the deployment of fungus, only very few animals required the anthelmintic treatment in fungus fed group. Gomez-Rincon et al. [48] observed excellent reduction in trichostrongyle infection in lambs given the fungus at the dose rate of $0.5 \times 10^{6}$ chlamydospores per kg body weight daily mixed in $100 \mathrm{~g}$ of barley. We [95] at CSWRI also evaluated the dosage scheduling in sheep and found effective delivery of $6 \times 10^{6}$ chlamydospores daily for 6 weeks for controlling H. controtus larvae in pasture.

\section{Biological control and animal performance}

Research results are available from all over the world showing parasitological as well as animal performance benefits of the strategic use of D. flagrans against GI nematodes of small ruminants. We can assess the relevance of fungus in controlling GI nematodes by looking into the research results from temperate/ sub temperate and tropical/ subtropical regions of the world. Among temperate/ sub temperate regions, Denmark ranks first where Githigia et al. [19] assessed the preventa $\neg$ tive effects of $D$. flagrans under field conditions in lambs. With regards to the tropical/ subtropical regions of the world, a survey conducted yielded 16 isolates of $D$. flagrans from fresh faecal samples collected from grazing livestock in Australia [15]. In USA, Pena et al. [102] found the fungus highly effective in reducing $H$. contortus larvae in faeces of sheep. In Louisiana (USA), daily feeding of fungus to grazing ewes reduced larval population in faeces which reduced pasture infectivity and subsequently nematode burden in tracer lambs [103]. The daily feeding of spores was found effective in reducing a predominantly H. contortus population on pasture. From 2002 to 2004 , three field trials carried out by Larsen [104] demonstrated a positive effect on production with increased weight gains in lambs after feeding chlamydospores daily to ewes and lambs for two months in the first half of the grazing season. Fungus could pass well through both sheep and goat and was equally effective against GI nematodes in laboratory faecal cultures [105]. The evaluation of D. flagrans on the two farms in Sweden from 2001 to 2003 was the only set of trials that had overall positive results. FEC and worm burdens were comparatively low throughout the evaluated time, indicating that the farms had reasonably good helminths control strategies [106]. In the mountain regions of Spain, D. flagrans spores fed to sheep at critical times of GIN epidemiology resulted into significant reduction in larval numbers on pasture, which could further improve lamb performance [48].

Contrary to this, another field trial undertaken in Northern Germany investigated the influence of D. flagrans on the in $\neg$ fection risk for sheep and goats under set-stocked conditions and found no significant differences in FEC or pasture infectivity between control and fungus receiving sheep [107]. Similarly, Eysker et al. [108] evaluated the efficacy of feeding fungal spores on parasitic gastroenteritis in lambs kept under an evasive grazing system in the Netherlands and observed a high reduction in yield as a result of fungal application in the faecal cultures but no differences between groups for FEC, pasture larval counts, worm counts and weight gain. Faessler et al. [109] also found significant suppression of larval development in faecal cultures during the fungus feeding period but no significant effect on the parasitological parameters when adult sheep were given fungus chlamydospores on three farms in Switzerland. 


\section{Combinatorial approach}

In most of parasitism, the economic losses are actually not attributable to mortality but due to impaired productivity of animals. In view of increasing incidence of anti-parasitic drug resistance in animals, there is an urgent need to design sustainable parasite control strategy which must include on the host as well as off the host control measures to harvest the maximum productivity from the animal [110]. Combination of more than one strategy always plays a significant role to control GIN infection in grazing ruminants, but a very few systematic studies have been conducted so far. In India, CSWRI has undertaken some studies to assess the effect of biological (nematophagous fungi, $D$. flagrans) control in association with dietary supplementation strategy by delivering the fungus in complete feed block (CFB) post-grazing [95]. Since night housing of sheep and goat is a common practice in our production system, administration of fungus through CFB seems to be a practical way of employing biological control agent. It may thus be recommended that in times of deficit feed intake from grazing, the delivery of nematophagous fungi through CFB would be of added advantage of meeting the minimum feed and nutrient intake, specifically the CP requirement in grazing ruminants, thereby integrating nutritional and biological control. Further, drenching animals with an effective antinematicidal medicinal plant before releasing them for grazing is a main factor to control nematodiasis as the pasture is less likely to be contaminated with nematode larvae for subsequent infection. Further, combining nutritional supplementation and phytotherapy with biological control seems more practical, feasible and suitable to combat GI parasitism in grazing ruminants. The likely responses are i) presence of indirect synergism between both substitutes (supplementary diets improve immune system of infected animals, whilst ethnobotanicals kill worms); ii) nematophagous fungi lessens pasture worm burden; iii) better nutritional status provides increased resilience; iv) supplemental feeding post-grazing ameliorates periodic and hidden nutritional deficiency. Besides, the alternatives are easily available, economically reasonable, culturally acceptable by the farmers, environmental friendly, relatively safe and has no residual effects on food chain. We believe strongly that this combined approach will solve the essence of the problem including anthelmintic resistance if accompanied with pasture rotation.

\section{Conclusion}

Increasing incidence of anthelmintic resistance, increasing awareness of issues involving environmental contamination with chemicals and consumer pressure to reduce drug residues in meat and meat products demand an alternate non-chemical parasite control strategies. D. flagrans is considered the most promising species for biological control against GIN infestation of livestock. The success of this strategy depends on survival of fungus in the gut and pass out onto the pasture through faeces prevent infective larval development for subsequent control in grazing animals. The nutrition-parasite interaction and the fact that long-term effect of $D$. flagrans on animals' levels of infection could be affected by a differential immune response, emphasizes to explore to what extent an enhancement in the animals immune response through nutritional intervention could improve the fungus efficacy as a practical biological control agent of parasitic nematodes in pastured ruminants. In this endeavour, combining nutritional input and ease in delivery of fungal zoospore through supplementation of feed block has promise to provide both protection against parasitism and resilience in sheep flock that are subjected to seasonal feed deprivation and thereby sustaining production.

Reduction in pasture infectivity will be an important advancement in small ruminant production and D. flagrans has the potential to be used for the purpose. However, it should not be considered as an agent to completely control GIN in livestock. It must be a part of an integrated control system utilizing minimum chemotherapy, grazing management, vaccine and other novel methods such as condensed tannins and utilizing genetically resistant breeds of sheep. The advantage that the fungus will have is that it has the potential to reduce the dependence on anthelmintics thereby addressing the concerns of drug resistance development, residues in meat and increased environmental toxicity.

\section{Authors' Contributions}

First author contributed to nutritional role and combinatorial approach while the second author to biological control of GIN. Both the authors read and approved the final manuscript.

\section{References}

1. Singh D, Swarnkar CP, Khan FA, Bhagwan PSK (1995) Resistance to albendazole in gastrointestinal nematodes of sheep. J Vet Parasitol 9: 95-8.

2. Singh D, Swarnkar CP, Srivastava CP, Bhagwan PSK (1996) Haemonchus contortus resistant to rafoxanide in sheep. J Vet Parasitol 10: 53-6.

3. Swarnkar CP, Sanyal PK, Singh D, Khan FA, Bhagwan PS (2001) Anthelmintic resistance in an organized sheep farm in India. Trop Anim Health Prod 33: 305-12.

4. Swarnkar CP, Singh D, Khan FA, Bhagwan PSK (1999) Multiple anthelmintic resistance in Haemonchus contortus of sheep. Ind J Anim Sci 69: 547-9.

5. Shalaby HA (2013) Anthelmintics resistance; How to overcome it? Iran J Parasitol 8: 18-32.

6. Grønvold J, Wolstrup J, Nansen P, Henriksen SA, Larsen M, et al. (1993) Biological control of nematode parasites in cattle with nematode- trapping fungi: a survey of Danish studies. Vet Parasitol 48: 311-25.

7. Larsen M (2000) Prospects for controlling animal parasitic nematodes by predacious micro fungi. Parasitology 120: S121-31.

8. Knox MR, Faedo M (2001) Biological control of field infections of nematode parasites of young sheep with Duddingtonia flagrans and effects of spore intake on efficacy. Vet Parasitol 101: 155-60.

9. Sanyal PK (2001) Biological control of Haemonchus contortus in sheep by nematophagous fungus, Duddingtonia flagrans. Indian Vet J 78: 1091-4. 
10. Paraud C, Chartier C (2003) Biological control of infective larvae of a gastro-intestinal nematode (Teladorsagia circumcincta) and small lungworm (Muellerius capillaris) by Duddingtonia flagrans in goat faeces. Parasitol Res 89: 102-6.

11. Wright DA, McAnulty RW, Noonan MJ, Stankiewicz M (2003) The effect of Duddingtonia flagrans on trichostrongyle infections of Saanen goats on pasture. Vet Parasitol 118: 61-9.

12. Parnell IW, Gordon HM (1963) Predaceous Fungi: A possible method of biological control of parasitic nematodes. J Helminthol 37: 339-42.

13. Larsen M, Wolstrup J, Henriksen SA, Grønvold J, Nansen P (1992) In vivo passage of nematophagous fungi selected for biocontrol of parasitic nematodes. J Helminthol 66: 137-41.

14. Waller PJ, Faedo M, Ellis K (2001) The potential of nematophagous fungi to control the free-living stages of nematode parasites of sheep: towards the development of a fungal controlled release device. Vet Parasitol 102: 299-308.

15. Larsen M, Faedo M, Waller PJ (1994) The potential of nematophagous fungi to control the free living stages of nematode parasites of sheep: Survey for the presence of fungi in fresh faeces of grazing livestock in Australia. Vet Parasitol 53: 275-81.

16. Hay FS, Niezen JH, Miller C, Bateson L, Robertson H (1997) Infestatation of sheep dung by nematophagous fungi and implications for the control of free living stages of gastrointestinal nematodes. Vet Parasitol 70: 247-54.

17. Ghahfarokhi MS, Abyaneh MR, Bahadori SR, Eslami A, Zare R, et al. (2004) Screening of soil and sheep faecal samples for predacious fungi: Isolation and characterization of the nematode-trapping fungus Arthrobotrys oligospora. Iran Biomed J 8: 135-42.

18. Wolstrop J, Gronvold J, Henriksen SA, Nansen P, Larsen M, et al. (1994) An attempt to implement the nematode- trapping fungus Duddingtonia flagrans in biological control of free-living stages of trichostrongyles in first year grazing calves. J Helminthol 68: 175-80.

19. Githigia SM, Thamsborg SM, Larsen M, Kyvsgaard NC, Nansen P (1997) The preventive effect of the fungus Duddingtonia flagrans on trichostrongyle infections of lambs on pasture. Int J Parasitol 27: 931-9.

20. Faedo M, Barnes EH, Dobson RJ, Waller PJ (1998) The potential of nematophagous fungi to control the free-living stages of nematode parasites of sheep: Pasture plot study with Duddingtonia flagrans. Vet Parasitol 76: 129-35.

21. Hashmi HA, Connan RM (1989) Biological control of ruminant trichostrongylids by Arthrobotrys oligospora, a predacious fungus. Parasitol Today 5: 28-30.

22. Manueli PR, Waller PJ, Faedo M, Mahommed F (1999) Biological control of nematode parasites of livestock in Fiji: screening of fresh dung of small ruminants for the presence of nematophagous fungi. Vet Parasitol 81: 39-45.

23. Saumell CA, Padilha TC, SantosC, de P, Roque MVC (1999) Nematophagous fungi in fresh feces of cattle in the Mata region of Minas Gerais state, Brazil. Vet Parasitol 82: 217-20.

24. Chandrawathani P, Jamnah O, Waller PJ, Höglund J, Larsen M, et al. (2002) Nematophagous fungi as a biological control agent for nematode parasites of small ruminants in Malaysia: a special emphasis on Duddingtonia flagrans. Vet Res 33: 685-96.

25. Silva AR, Araújo JV, Braga FR, Frassy LN, Tavela AO, et al. (2009) Biological control of sheep gastrointestinal nematodiosis in a tropical region of the southeast of Brazil with the nematode predatory fungi Duddingtonia flagrans and Monacrosporium thaumasium. Parasitol Res 105: 1707-13.

26. Braga FR, de Araújo JV (2014) Nematophagous fungi for biological control of gastrointestinal nematodes in domestic animals. Appl Microbiol Biotechnol 98: 71-82.

27. Silva ME, Braga FR, Borges LA, Oliveira JM, Lima Wdos S, et al. (2014) Evaluation of the effectiveness of Duddingtonia flagrans and Monacrosporium thaumasium in the biological control of gastrointestinal nematodes in female bovines bred in the semiarid region. Vet Res Commun 38: 101-6.

28. Sanyal PK (2000) Presence of predacious fungi in fresh faeces of ruminants from western India. J Vet Parasitol 14: 133-5.

29. Khan FA, Swarnkar CP, Singh D, Bhagwan PSK, Dubey SC (2001) Nematophagous fungi isolated from sheep faeces: a promising biological control of Haemonchus contortus. Ind J Anim Sci 71: 834-6.

30. Khan FA, Singh D, Swarnkar CP, Tiwari R, Tiwari J (2009) Biological control of gastrointestinal nematodes of sheep in Rajasthan state (India): Screening of nematophagous fungi locally isolated from fresh faeces of sheep. Ind J Anim Sci 79: 9-11.

31. Sanyal PK (2000) Screening for Indian isolates of predacious fungi for use in biological control against nematode parasites of ruminants. Vet Res Commun 24 : 55-62.

32. Khan FA, Swarnkar CP, Singh D, Bhagwan PSK, Dubey SC (2002) Predacious activity of Duddingtonia flagrans against Haemonchus contortus larvae in faeces after passage through the gastrointestinal tract of sheep. Ind J Anim Sci 72: 559-60.

33. Khan FA, Sahoo A, Dixit SK (2015) Evaluation of administering Duddingtonia flagrans through complete feed block for controlling Haemonchus contortus in sheep. Anim Nutr Feed Technol (In Press).

34. van Houtert MEJ, Sykes AR (1996) Implications of nutrition for the ability of ruminants to withstand gastrointestinal nematode infections. Intl J Parasitol 26: 1151-67

35. Sahoo A, Khan FA, Karim SA (2011) A review on nutrition and gastro-intestinal nematode parasitism: interaction and implications in ruminant livestock. Indian J Small Rum 17: 1-20.

36. Abbott EM, Parkins JJ, Holmes PH (1986) The effect of dietary protein on the pathogenesis of acute ovine haemonchosis. Vet Parasitol 20: 275-89.

37. Abbott EM, Parkins JJ, Holmes PH (1988) Influence of dietary protein on the pathophysiology of haemonchosis in lambs given continuous infections. Res Vet Sci. 45: 41-9.

38. Datta FU, Nolan JV, Rowe JB, Gray GD (1998) Protein supplementation improves the performance of parasitised sheep fed a straw-based diet. Int J Parasitol 28: 1269-78.

39. Sykes AR, Geer AW (2003) Effects of parasitism on the nutrient economy of sheep. Aust J Exp Agric 43: 1393-98.

40. Symons LE (1985) Anorexia:occurrence, pathophysiology and possible causes in parasitic infections. Adv Parasitol 24: 103-33.

41. Coop RL, Huntley JF, Smith WD (1995) Effect of dietary protein supplementation on the development of immunity to Ostertagia circumcincta in growing lambs. Res Vet Sci 59: 24-9.

42. Kahn LP (2003) Regulation of the resistance and resilience of periparturient ewes to infection with gastrointestinal nematode parasites by dietary supplementation. Aus J Exp Agric 43: 1477-85.

43. Coop RL, Holmes PH (1996) Nutrition and parasite interaction. Intl J Parasitol 26: 951-62. 
44. Yu F, Bruce LA, Calder AG, Milne E, Coop RL, et al. (2000) Subclinical infection with the nematode Trichostrongylus colubriformis increases gastrointestinal tract leucine metabolism and reduce leucine availability to other tissues. J Anim Sci 78: 380-90.

45. Lord G (2002) Role of leptin in immunology. Nutr Rev 60: S35-8.

46. Valderrábano J, Delfa R, Uriarte J (2002) Effect of level of feed intake on the development of gastrointestinal parasitism in growing lambs. Vet Parasitol 104: 327-38.

47. Torres-Acosta JF, Jacobs DE, Aguilar-Caballero A, Sandoval-Castro C, May-Martinez M, et al. (2004) The effect of supplementary feeding on the resilience and resistance of browsing Criollo kids against natural gastrointestinal nematode infections during the rainy season in tropical Mexico. Vet Parasitol 124: 217-38.

48. Gómez-Rincón C, Uriarte J, Valderrábano J (2007) Effect of nematophagous fungus Duddingtonia flagrans and energy supplementation on the epidemiology of naturally infected kids. Vet Res 38: 141-50.

49. Valderrábano J, Gómez-Rincón C, Uriarte J (2006) Effect ofnutritionalstatus andfat reserves on the periparturient immune response to Haemonchus contortus infection in sheep. Vet Parasitol 141: 122-31.

50. van Houtert MF, Barger IA, Steel JW, Windon RG, Emery DL (1995) Effects of dietary protein intake on responses of young sheep to infection with Trichostrongylus colubriformis. Vet Parasitol 56: 163-80.

51. Knox M, Steel J (1996) Nutritional enhancement of parasite control in small ruminant production systems in developing countries of South-East Asia and the Pacific. Int J Parasitol 26: 963-70.

52. Coop RL, Kyriazakis I (1999) Nutrition-parasite interaction. Vet Parasitol 84: 187-204.

53. Etter E, Hoste H, Chartier C, Pors I, Koch C, et al. (2000) The effect of two levels of dietary protein on resistance and resilience of dairy goats experimentally infected with Trichostrongylus colubriformis: comparison between high and low producers. Vet Res 31: 247-58.

54. Ezenwa VO (2004) Interactions among host diet, nutritional status and gastrointestinal parasite infection in wild bovids. Intl J Parasitol 34: 535-42.

55. Louvandini H, Veloso CF, Paludo GR, Dell'Porto A, Gennari SM (2006) Influence of protein supplementation on the resistance and resilience on young hair sheep naturally infected with gastrointestinal nematodes during rainy and dry seasons. Vet Parasitol 137: 103-11.

56. Khan FA, Sahoo A, Dhakad S, Pareek AK, Karim SA (2011) Effect of trickle infection with Haemonchus contortus on pathophysiology and metabolic responses of growing lambs. Ind J Anim. Sci 81: 1005-9.

57. Khan FA, Sahoo A, Sonawane GG, Karim SA, Dhakad S, et al. (2012) Effect of dietary protein on responses of lambs to repeated Haemonchus contortus infection. Livestock Sci 150: 143-51.

58. Pathak AK, Dutta N, Banerjee PS, Pattanaik AK, Sharma K (2013) Influence of Dietary supplementation of condensed tannins through leaf meal mixture on intake, nutrient utilization and performance of Haemonchus contortus infected sheep. Asian-Aust J Anim Sci 26: 1446-58.

59. Houdijk JG, Jackson F, Coop RL, Kyriazakis I (2006) Rapid improvement of immunity to Teladorsagia circumcincta is achieved through a reduction in the demand for protein in lactating ewes. Intl J Parasitol 36: 219-27.

60. Hughes S, Kelly P (2006) Interactions of malnutrition and immune impairment, with specific reference to immunity against parasites. Parasite Immunol 28: $577-88$.

61. Keen CL, Gershwin ME (1990) Zinc deficiency and immune function. Annu Rev Nutr 10: 415-31.

62. Scott ME, Koski KG (2000) Zinc deficiency impairs immune responses against parasitic nematode infections at intestinal and systemic sites. J Nutr 130: 1412S-20S.

63. Coop RL, Field AC (1983) Effect of phosphorus intake on growth rate, food intake and quality of the skeleton of growing lambs infected with the intestinal nematode Trichostrongylus vitrinus. Res Vet Sci 38: 175-81.

64. Barrel GK (1997) Sustainable Control of Internal Parasites in Ruminants, Lincoln University, Canterbury, New Zealand.

65. Suttle NF, Knox DP, Angus KW, Jackson F, Coop RL (1992) Effects of dietary molybdenum on nematode and host during Haemonchus contortus infection in lambs. Res Vet Sci 52: 230-5.

66. McLure SJ, McLure TJ, Emery DL (1999) Effect of molybdenum on primary infection and subsequent challenge by nematode parasite Trichostrongylus colubriformis in weaned Merino lambs. Res Vet Sci 67: 17-22.

67. Burke JM, Miller JE, Larsen M, Terrill TH (2005) Interaction between copper oxide wire particles and Duddingtonia flagrans in lambs. Vet Parasitol 134: 141-6. 68. Villamor E, Fawzi WW (2005) Effects of vitamin a supplementation on immune responses and correlation with clinical outcomes. Clin Microbiol Rev 18: 44664.

69. Gruner TM, Sedcole JR, Furlong JM, Sykes AR (2009) Vitamin B12 absorption and metabolism in milk-fed lambs. N Z Vet J 57: 22-7.

70. Hammond JA, Fielding D, Bishop SC (1997) Prospect for plant anthelmintics in Tropical Veterinary Medicine. Vet Res Commun 21: 213-28.

71. Iqbal Z, Nadeem KQ, Khan MN, Waraich FN (2001) Anthelmintic activity of Allium satvium, Zingiber officinale, Curcurbita mexicana and Ficus religiosa. Int J Agri Biol 4: 451-3.

72. Cala AC, Chagas AC, Oliveira MC, Matos AP, Borges LM, et al. (2012) In vitro anthelmintic effect of Melia azedarach L. and Trichilia claussenii C. against sheep gastrointestinal nematodes. Exp Parasitol 130: 98-102.

73. Jain P, Singh S, Singh SK, Verma SK, Kharya MD, et al. (2013) Anthelmintic potential of herbal drugs. Intl J Res Dev Pharm Life Sci 2: 412-27.

74. Sujon MA, Mostofa M, Jahan MS, Das AR, Rob S (2008) Studies on medicinal plants against gastroinstestinal nematodes of goats. Bangl J Vet Med 6: 179-83.

75. Balamurugan G, Selvarajan S (2009) Preliminary phytochemical screening and anthelmintic activity of Indigofera tinctoria Linn. Int J Drug Dev Res 1: 157-60.

76. Martin RJ (1997) Mode of action of anthelmintic drugs. Vet J 154: 11-34.

77. Athanasiadou S, Kyriazakis I, Jackson F, Coop RL (2001) Direct anthelmintic effects of condensed tannins towards different gastrointestinal nematodes of sheep: in vitro and in vivo studies. Vet Parasitol 99: 205-19.

78. Thomson DP, Geary TG (1995) The structure and function of helminth surfaces. Biochemistry and Molecular Biology of Parasites, Marr eds, New York, Academic Press, USA.

79. Athanasiadou S, Kyriazakis I (2004) Plant secondary metabolites: Antiparasitic effects and their role in ruminant production systems. Proc Nutr Soc 63: 631-9. 
80. Sahoo A, Sharma RK, Kurade NP, Bhat TK, Singh B (2004) Effect of tanniniferous top feed on parasitic load in calves in the North-West-Humid Himalayan region. J Appl Anim Res 25: 49-51.

81. Barrau E, Fabre N, Fouraste I, Hoste H (2005) Effect of bioactive compounds from Sainfoin (Onobrychis viciifolia Scop.) on the in vitro larval migration of Haemonchus contortus: role of tannins and flavonol glycosides. Parasitology 131: 531-8.

82. Swarnakar CP, Singh D, Khan FA, Vaithiyanathan S (2008) Effect of tanniferous plant (Prosopis cineraria) on Haemonchus contortus in sheep. Indian J Anim Sci 78: 951-3.

83. Zaman MA, Iqbal Z, Khan MN, Muhammad G (2011) Anthelmintic activity of a herbal formulation against gastrointestinal nematodes of sheep. Pakistan Vet J 32: 117-21.

84. Salifou S, Daga DF, Attindehou S, Deguenon R, Biaou CF (2013) Antiparasitic effects of the water extract from Chenopodium ambrosioides L. (Chenopodiaceae) against some gastrointestinal nematodes in West African Long Legged goats. J Parasitol Vector Biol 5: 13-6.

85. Kimani D, Kareru PG, Karanja JM, Njonge FK, Githira PN, et al. (2014) In-vivo activity of two herbal plant mixtures against gastrointestinal nematodes in ruminants. IOSR J Appl Chem 7: 21-8.

86. Githiori JB, Höglund J, Waller PJ (2005) Ethnoveterinary plant preparations as livestock dewormers: practices, popular beliefs, pitfalls and prospects for the future. Anim Health Res Rev 6: 91-103.

87. Waller PJ, Knox MR, Faedo M (2001) The potential of nematophagous fungi to control the free-living stages of nematode parasites of sheep: feeding and block studies with Duddingtonia flagrans. Vet Parasitol 102: 321-30.

88. Chandrawathani P, Jamnah O, Waller PJ, Larsen M, Gillespie AT, et al. (2003) Biological control of nematode parasites of small ruminants in Malaysia using the nematophagous fungus Duddingtonia flagrans. Vet Parasitol 117: 173-83.

89. Chandrawathani P, Jamnah O, Adnan M, Waller PJ, Larsen M, et al. (2004) Field studies on the biological control of nematode parasites of sheep in the tropics, using the microfungus Duddingtonia flagrans. Vet Parasitol 120: 177-87.

90. Rocha RA, Araujo JV, Amarante AF (2007) Efficacy of the nematode- trapping fungus Duddingtonia flagrans against infections by Haemonchus and Trichstrongylus species in lambs at pasture. J Helminthol 81: 387-92.

91. Casillas Aguilar JA, Mendoza de Gives P, López-Arellano ME, Liébano Hernández E (2008) Evaluation of multinutritional pellets containing Duddingtonia flagrans chlamydospore for the control of ovine Haemonchosis. Annals NY Acad Sci 1149: 161-3.

92. Santurio JM, Zanette RA, Da Silva AS, Fanfa VR, Farret MH, et al. (2011) A suitable model for the utilization of Duddingtonia flagrans fungus in small-flocksize sheep farms. Exp Parasitol 127: 727-31.

93. Anonymus (2001) Biotechnological Laboratory Report 2000-2001. National Dairy Development Board, Anand, India.

94. Khan FA, Singh D, Swarnkar CP, Bhagwan PSK, Dubey SC (2004) Nematode-trapping fungus, Arthrobotrys oligospora for biocontrol of Haemonchus contortus. J Vet Parasitol 18: 13-6.

95. Khan FA, Sahoo A, Satish K, Dixit SK (2015) Biological control of ovine gastrointestinal nematode by using nematophagous fungi. Report submitted to DST Rajasthan.

96. Faedo M, Larsen M, Thamsborg S (2000) Effect of different times of administration of the nematophagous fungus Duddingtonia flagrans on the transmission of ovine parasitic nematodes on pasture- a plot study. Vet Parasitol 94: 55-65.

97. Larsen M, Faedo M, Waller PJ, Hennessy DR (1998) The potential of nematophagous fungi to control the free living stages of nematode parasites of sheep: Studies with Duddingtonia flagrans. Vet Parasitol 76: 121-8.

98. Sanyal PK, Mukhopadhyaya PN (2003) Top dressing of feed with desiccated chlamydospores of Duddingtonia flagrans for biological control of the pre-parasitic stages of ovine Haemonchus contortus. Vet Res Commun 27: 381-90.

99. Terrill TH, Larsen M, Samples O, Husted S, Miller JE, et al. (2004) Capability of the nematode-trapping fungus Duddingtonia flagrans to reduce infective larvae of gastrointestinal nematodes in goat faeces in the southeastern United States: Dose titration and dose time interval studies. Vet Parasitol 120: 285-96.

100. Paraud C, Hoste H, Lefrileux Y, Pommaret A, Paolini V, et al. (2005) Administration of Duddingtonia flagrans chlamydospores to goats to control gastrointestinal nematodes: dose trials. Vet Res 36: 157-66.

101. Maingi N, Krecek RC, van Biljon N (2006) Control of gastrointestinal nematodes in goats on pastures in South Africa using nematophagous fungus, Duddingtonia flagrans and selective anthelmintic treatments. Vet Parasitol 138: 328-36.

102. Pena MT, Miller JE, Fontenot ME, Gillespie A, Larsen M (2002) Evaluation of the efficacy of Duddingtonia flagrans in reducing infective larvae of Haemonchus contortus in faeces of sheep. Vet Parasitol 103: 259-65.

103. Fontenot ME, Miller JE, Pena MT, Larsen M, Gillespie A (2003) Efficiency of feeding Duddingtonia flagrans chlamydospores to grazing ewes on reducing availability of parasitic nematode larvae on pasture. Vet Parasitol 118: 203-13.

104. Larsen M (2006) Biological control of nematodes in sheep. J Anim Sci 84: E133-9.

105. Waghorn TS, Leathwick DM, Chen LY, Skipp RA (2003) Efficacy of the nematode- trapping fungus Duddingtonia flagrans against three species of gastrointestinal nematodes in laboratory fecal cultures from sheep and goats. Vet Parasitol 118: 227-34.

106. Waller PJ, Schwan O, Ljungström BL, Rydzik A, Yeates GW (2004) Evaluation of biological control of sheep parasites using Duddingtonia flagrans under commercial farming conditions on the island of Gotland, Sweden. Vet Parasitol 126: 299-315.

107. Holst CR (2005) Studies on the influence nematophagous fungi on nematode infection risk Sheep and goats. Hanover: University of Veterinary Medicine/ Untersuchungen zum Einfluss nematophager Pilze auf das Nematoden-Infektionsrisiko bei Schafen und Ziegen.

108. Eysker M, Bakker N, Kooyman FN, Olthuis SO, Ploeger HW (2006) Effect of biological control through the daily application of spores of Duddingtonia flagrans in lambs kept under an evasive grazing system in the Netherlands. Vet Parasitol 140: 312-20.

109. Faessler H, Torgerson PR, Hertzberg H (2007) Failure of Duddingtonia flagrans to reduce gastrointestinal nematode infections in dairy ewes. Vet Parasitol 147: 96-102.

110. Kumar N, Rao TKS, Varghese A, Rathor VS (2013) Internal parasite management in grazing livestock. J Parasit Dis 37: 151-7. 


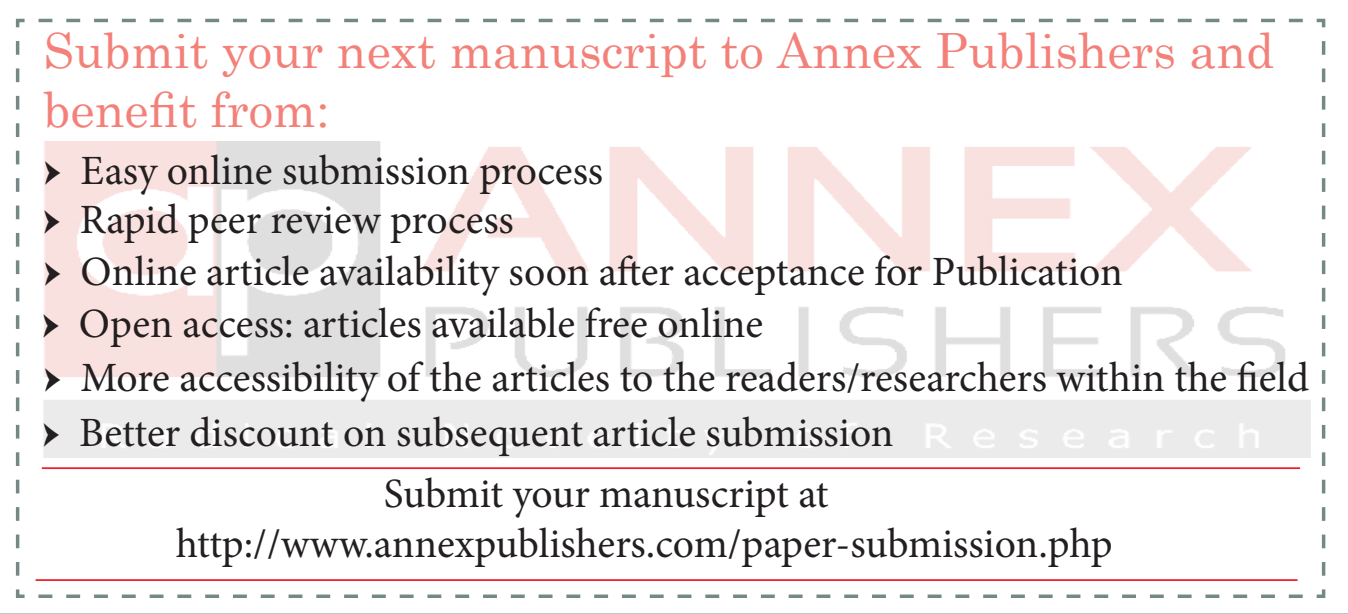

